\title{
Towards intensive parenting? Changes in the composition and determinants of mothers' and fathers' time with children 1992-2006
}

\author{
Lyn Craig, Abigail Powell and Ciara Smyth
}

\begin{abstract}
Contemporary expectations of good parenting hold that focused, intensive parental attention is essential to children's development. Parental input is viewed as a key determinant in children's social, psychological and educational outcomes, with the early years particularly crucial. However, increased rates of maternal employment mean that more parents are juggling work and family commitments and have less non-work time available to devote to children. Yet studies find that parental childcare time has increased over recent decades. In this paper, we explore the detail of this trend using data from the Australian Bureau of Statistics (ABS) Time Use Survey (TUS), 1992 and 2006.To investigate whether discourses on intensive parenting are reflected in behaviour, we examine a greater range of parent-child activities than has been undertaken to date, looking at trends in active childcare time (disaggregated into talk-based, physical and accompanying care activities); time in childcare as a secondary activity; time spent in the company of children in leisure activities; and time spent in the company of children in total. We also investigate whether the influence of factors known to predict parental time with children (gender, education, employment status and the age of children) have changed over time. We contextualize our analyses within social and economic trends in Australia and find a compositional change in parental time, with more active childcare occurring within less overall time, which suggests more intensive, child-centred parenting. Fathers' parent-child time, particularly in physical care, increased more than mothers' (from a much lower base), and tertiary education no longer predicts significantly higher childcare time.
\end{abstract}

Keywords: intensive parenting; parental childcare; mothers; fathers; time use

\section{Introduction}

In this paper, we use data from the Australian Bureau of Statistics (ABS) Time Use Survey (TUS) 1992 and 2006 to examine the trend over recent decades towards increased parental childcare time and whether there has been a shift towards more intensive parenting. We extend the literature by i) looking at change in a greater range of parent-child activities than previously studied (not only talk-based, physical and accompanying childcare activities, but also time spent in the company of children in leisure activities and time spent in the company of children in total), and ii) by exploring whether and how the impact of known predictors of parent-child time (gender, education, employment and age of children) have changed over this fifteen year time-span. We tease out which aspects of care have changed, and for which parents, with reference to changing discourses on parenting and to key developments in the family policy context in Australia between 1992 and 2006.

\section{Background}

Over recent decades, the cultural context of parenthood has shifted (Sayer et al. 2004a). Building on the work of Hays (1996), it is widely argued that the practice of parenting has intensified (Aurini and Davies 2005; Furedi 2001; Quirke 2006; Wall 2010; Wall 2004; Ehrenreich and English 2005). There has been substantial redefinition of the parenting role, which now encompasses responsibility for children's education and cognitive development (Wrigley 1989), in addition to their physical, emotional and social development (Furedi 2001; Reiger et al. 2009). Contemporary ideals of good parenting encompass significant time investments in children (Stearns 2003; Wall 2010; Sayer et al. 2004a), and there is broad consensus that the time parents devote to their children is vital to their healthy development (Monna and Gauthier 2008). While much of the discourse on parenting is focused on the intensification of motherhood, the expectation of heightened time investment is increasingly extended to fathers (Wall and Arnold 2007; Daly 2001).

The 'ever-widening definition of parenting' (Furedi 2001) has taken hold in the same period that maternal labour force participation has increased. More families are dual-earner households, reducing the amount of nonwork time available to children (ABS 2009; Bianchi et al. 2006; Coltrane and Adams 2008). Yet, despite the time-squeeze that many working parents face, there is evidence that in most western countries, parents are in fact devoting more time to childcare than parents of the 1960s, when the majority of mothers were home full- 

forthcoming). This suggests that behavioural changes in parenting practices have outweighed structural changes such as increased maternal workforce participation (Sandberg and Hofferth 2001; Sayer et al. 2004a).

While the trend towards increased parental childcare time is well established, less is known about the detail of how that time is spent. This is a significant gap in knowledge, because time spent with children comprises a multitude of activities and changes may not be uniform across activities. To address this gap, this paper explores changes in the composition, as well as the amount, of parental childcare.

Much of the time that home-based mothers used to spend with children was not devoted to direct childcare or shared activities, but rather consisted of supervising and monitoring them while doing other tasks such as housework (Hofferth 2001). If parenting is becoming more intensive, we would expect the time that parents are actively engaged in talking to or playing with their children, or attending to their physical needs, to take priority over time supervising them without active involvement. The term 'quality time' is often used to capture interactive, developmentally-focused time (Baxter 2010) in which parent and child are engaged in activities such as reading or helping with homework (for a discussion see Bittman et al. 2004). A trend towards intensive parenting should result in an increase in this 'quality time' and a decline in unstructured time, particularly if non-work time is scarce. Furthermore, growth in formal childcare use, associated with increased maternal employment, may mean parents spend more time accompanying children to and from day care or nursery school. Moreover, cross-sectional research suggests that the transfer of physical care activities such as feeding or changing nappies to substitute carers is far less than one-for-one (Craig 2007b). In this paper, we examine interactive talk-based care, physical and accompanying care, and supervisory care independently, and can thus see if there have been different patterns of change or trade-offs between them.

A further indication of increasing child-focus may be willingness to forgo adult-only leisure time in favour of sharing recreation with children. As ideals of family life change, leisure with children has become regarded as an increasingly important aspect of parenting (Daly 2001; Milkie et al. 2004). Shared leisure can facilitate family bonding, and be pleasant downtime for parents and fun for children. Joint family time, when both parents are together with children, is particularly valued in cementing good family relationships (Craig and Mullan 2012) and can also broaden children's knowledge through 'purposive' activities such as visiting museums, the zoo or art galleries (Shaw and Dawson 2001; Shaw 2008). A growth in joint parent-child leisure may therefore be another manifestation of intensive parenting, in that it is intended to serve the emotional and educational needs of children. This paper addresses this issue by looking at compositional changes in overall time spent in the company of children. Time in the company of children is a more encompassing measure that includes not only active childcare time, but all time parents and children are together regardless of what they are doing and we investigate if more of this time is now devoted to leisure with children.

\section{Australian context}

Of course, evolving child-raising practices and beliefs about the proper care of children are, to a large extent, collectively produced (Duncan and Edwards 2003). They are mediated through cultural norms and values, and are also reflexively influenced by workplace structures and economic and family policy (Gornick and Meyers 2009). It is therefore important to describe the Australian context in which this study is situated.

Australia is usually grouped with the USA, the UK, Canada, and New Zealand as a 'liberal' welfare state, in which work-family reconciliation and raising children are seen as largely private, not state, responsibilities (Pocock 2005; Orloff 2009; Gornick and Meyers 2003), but it also has distinctive features. Policies and social and economic conditions changed somewhat over the period 1992-2006, moreover. In 1992, Australia was governed by the progressive Labor Party, but in 1996, the socially conservative National-Liberal Party Coalition was elected to power, where it remained for the next 11 years (Craig et al. 2010).

Between 1992 and 2006, Australia experienced economic growth, tertiary education rates increased, particularly for women, and the unemployment rate fell. Paid work hours for full-time employees rose, to the point that fulltime working hours are among the highest in the OECD (OECD 2006). More women entered the labour force, although a particular feature of Australia is a very high incidence of female part-time work (OECD 2006). Most families with young children are 1.5 earner households (in which father works full-time, mother works part time) and this was further reinforced following the 1996 change of government. The National-Liberal Coalition introduced a generous benefit payment for families with dependent children, calculated on the income of the 

household's secondary earner, which created substantial disincentives for mothers to take up full-time paid work (Apps 2006; Toohey and Beer 2004).

Legislation enshrines formal equal employment opportunity (OECD 2007). However, successive governments resisted calls for mandated paid maternity leave (Whitehouse et al. 2007), with the result that until 2011 Australia was one of only two OECD countries without a national scheme (Craig et al. 2010). In Australia, most formal early education and childcare is purchased privately, although there are some state subsidies. It is also highly regulated and is generally of good quality (Brennan 1998). Over the period 1992-2006, childcare places and the use of formal childcare increased. However, demand exceeded supply and costs grew; from 2002, childcare costs increased annually by an average 12 per cent. Despite the increase in use, long-hours, full-time, non-parental childcare is not the norm among young Australian children, with the majority attending for less than 20 hours per week (ABS 2006). Australian parents spend the most time caring for children of all OECD countries (Fisher and Robinson 2010).

Previous research has found that against this background Australian households with children increased their time commitments to both paid work and childcare (Craig et al. 2010). In this paper, we add to knowledge by examining the composition of this change. We also know from previous research that a range of factors impact on parent-child time, including gender, education level, employment and age of children. We make a further contribution by examining whether the effects of these factors have remained constant across the range of parent-child time measures in Australia between 1992 and 2006.

\section{Factors influencing time with children}

\section{Gender}

The literature on parenting draws attention to the emergence of the engaged, active, involved father. The general consensus is that today's fathers are more involved in their children's lives than previous generations (Cabrera et al. 2000; Flouri 2005; Sayer et al. 2004a; Smith 2004; Sullivan 2006; Yeung et al. 2000). Nevertheless, time use studies consistently find that mothers spend more time with their children than do fathers (Nomaguchi et al. 2005; Sayer et al. 2004a; Craig 2006a; Craig 2007a; Mannino and Deutsch 2007), and suggest that fathers do not participate equally across the full range of care activities. Mothers spend a greater proportion of their total care time in physical and routine care activities than fathers do, while fathers are more likely to engage in play, talking, educational, supervisory and leisure activities than in other forms of care (Hook and Wolfe 2012; Craig 2006b). They are also much more likely to spend time with children together with their partners, rather than looking after the children solo (Craig and Mullan 2011). None the less, there is time use evidence that in some countries, fathers now participate in an increasingly wide range of parent-child activities (Hook and Wolfe 2012). We expect to find this applies in the Australian context. At the same time, we expect gender divisions in care time to remain strong, reflecting the policy environment described above, which inter alia engenders very different average working hours for mothers and fathers. Taking these influences together, we hypothesize that Australian fathers' total time with children will not have increased over the period 1992-2006, but that the composition of that time will have changed to be more child-focused, and will include more direct care of children.

\section{Education}

Previous research has found that parents' education level is positively associated with childcare time, particularly in more cognitively stimulating activities (Sayer et al. 2004b; Craig 2006c; Baxter and Hayes 2007; Bonke and Esping-Andersen 2011). This may be related to class, as the normative view that young children need constant and sustained parental attention is thought to be most prevalent among the middle classes (Lareau 2003; Wall 2010; Vincent and Ball 2007). Lareau (2003) for example, argues that middle-class parents engage in the 'concerted cultivation' of their children to help them reach their full potential and ensure that they do well academically in an increasingly competitive environment. Moreover, focused parental inputs transfer human capital across the generations (Bonke and Esping-Andersen 2011). Yet while the connection between parental education and more childcare time is well-established, the link is not universal, does not apply to all types of parent-child time, and may even be weakening. Associations between maternal education and childcare (not disaggregated by activity type) have been found non-significant in Germany, but strong in Austria (Berghammer 2012). In the USA, a study looking specifically at cognitively-based childcare found the strength of association with maternal education weakened in the final decade of the twentieth century (Schaub 2010). In a crosssectional study, Baxter (2010) found that inAustralia higher levels of parental education were not associated 
with overall parent-child time after controlling for other factors. The marked growth in tertiary education in Australia may mean that it is no longer the marker of class it once was, and that middle-class norms and aspirations for children have become more widespread. In any event, we expect education would have more effect on active childcare activities than on overall time with children, but also that the significance of education on all aspects of parent-child time will have diminished over time.

\section{Employment}

Employment is negatively associated with parental time investment in children, with working parents spending less time with their children than their non-working counterparts (Sayer et al. 2004a; Baxter 2009). However, research indicates that the size of this effect is small and that, as noted above, contemporary parents spend more time with their children than in the heyday of the male breadwinner/female homemaker family (Bianchi et al. 2006; Gauthier et al. 2004; Sayer et al. 2004a). In Australia, most fathers work fulltime and their time in specific childcare activities varies little by employment status (Craig 2007a). Working mothers have been found to protect time in active care by shifting the time of day at which they perform activities, and giving up sleep, housework and personal care (Craig 2007b). However, unstructured time with children is more affected by employment than active care, with working parents averaging less time in supervisory care than nonworking parents (Hofferth 2001; Craig 2007c). We expect leisure time with children to be similarly affected. Further, given the increase in Australian full-time working hours between 1992 and 2006, we expect to find that the effect of employment on unstructured and leisure time has increased, particularly for fathers. We do not anticipate the effect of employment on active childcare will be very marked, but the rise in maternal employment may mean there are stronger selection effects, which cause growing disparity between the parentchild time of employed and stay-at-home mothers.

\section{Age of children}

Time with children is particularly high when children are young and tapers off as they get older (Craig and Sawrikar 2009). This makes sense, as young children's care needs are most pressing, and they require constant supervision. However, there are reasons to expect that the focus on very young children will have increased over time, with growing emphasis on the importance of children's 'early years'. Messages concerning the importance of early education, appropriate stimulation and secure attachments to enhance children's brain capacity have dominated parenting policy and advice literature since the 1990s (Furedi 2001; Nadesan 2002; Quirke 2006; Wall 2004; Wall 2010; Bruer 1999). The thrust of this neuro-science-based advice is that a child's early years are critical to their later success; that the first three years of life represent a window of opportunity that can never be recovered. Although the science underlying these claims has been questioned (Bruer 1999), the discourse that permeates contemporary parenting advice may increase 'pressure to conform to a model of intensive parenting' (Wall 2004). We would expect the trend towards greater time investment in children to apply particularly to pre-school children in Australia, given the relatively low use of formal childcare and the emphasis on parental care noted above.

In summary, this study explores the detail of the growth in parental childcare time, within the Australian context between 1992 to 2006, to determine whether parenting practices have intensified. We extend existing research by examining change over time in a greater range of parent-child activities than previously studied, because evidence of changing parental practice is to be found in the composition, as well as in the quantity, of time spent. We also identify whether and how the impact of known predictors of parent-child time (gender, education, employment and age of children) has changed over time.

\section{Methodology}

\section{Data}

We analyse data from the Australian Time Use Surveys (1992 and 2006)1. These data contain nationally representative samples of the population of Australian households. All individuals aged 15 years and over in sampled households provide time use information. This means that in couple households we have information from both partners. Respondents are asked to record their main (primary) activities, any simultaneous (secondary) activity they engage in, who they are with and where they are throughout the day, to a detail level of five minute intervals. The 1992 and 2006 datasets were harmonized to ensure comparability and weights supplied with the data are used to correct other differences such as the oversampling of weekend days in 2006. Our sample is couple households, either married or cohabiting, aged 20-59 years with at least one child aged 0- 
14 years, because the TUS only collects childcare data for children in this age range. This yields a sample of 1634 households who completed the diary on one or two days $(1992 \mathrm{n}=880 ; 2006 \mathrm{n}=754)$, resulting in a total 3198 completed diary days2. In all of these households, there are observations for both parents. Sample characteristics are summarized in Table I.

Table I: Sample characteristics

\begin{tabular}{|c|c|c|c|c|c|}
\hline & & \multicolumn{2}{|c|}{$\underline{1992}$} & \multicolumn{2}{|c|}{$\underline{2006}$} \\
\hline & & Mothers & Fathers & Mothers & Fathers \\
\hline$N$ & & 880 & 880 & 754 & 754 \\
\hline \multirow[t]{2}{*}{ Education } & No degree & 90.0 & 82.2 & 71.6 & 74.7 \\
\hline & Has a degree & 10.0 & 17.8 & 27.8 & 24.7 \\
\hline \multirow[t]{3}{*}{ Employment } & Works full-time & 20.4 & 85.5 & 24.1 & 88.2 \\
\hline & Works part-time & 39.5 & 5.2 & 46.2 & 5.5 \\
\hline & No paid work & 40.1 & 9.2 & 29.7 & 6.3 \\
\hline \multirow[t]{3}{*}{ Age of youngest child } & $0-4$ years & \multicolumn{2}{|c|}{47.6} & \multicolumn{2}{|c|}{46.2} \\
\hline & $5-9$ years & \multicolumn{2}{|c|}{26.1} & \multicolumn{2}{|c|}{28.2} \\
\hline & $10-14$ years & \multicolumn{2}{|c|}{26.3} & \multicolumn{2}{|c|}{25.4} \\
\hline \multirow[t]{3}{*}{ Number of children } & 1 child & \multicolumn{2}{|c|}{36.6} & \multicolumn{2}{|c|}{36.6} \\
\hline & 2 children & \multicolumn{2}{|c|}{40.9} & \multicolumn{2}{|c|}{44.3} \\
\hline & 3 or more children & \multicolumn{2}{|c|}{22.8} & \multicolumn{2}{|c|}{19.1} \\
\hline \multirow[t]{2}{*}{ Use of formal childcare } & Uses formal care & \multicolumn{2}{|c|}{27.8} & \multicolumn{2}{|c|}{33.2} \\
\hline & Does not use formal care & \multicolumn{2}{|c|}{72.2} & \multicolumn{2}{|c|}{66.8} \\
\hline
\end{tabular}

Note: Figures may not sum to $100 \%$ due to missing data.

Table I highlights a number of differences between mothers and fathers and between the sample in 1992 and 2006. The proportion of parents educated to degree level increased substantially over this fifteen-year period, particularly for mothers. Thus, while fathers were more likely to be educated to degree level in 1992, by 2006 mothers were more likely to have a degree than fathers. Fathers were more likely to work full-time than mothers, and in 2006 mothers were less likely to be out of the workforce compared to 1992. The profile of children (age and number of children) in couple households has stayed broadly similar over time.

\section{Dependent variables}

The dependent variables we examine are:

1) Childcare as a primary (main) activity. Primary childcare is disaggregated by activity, into i) interactive talk-based care including talking, listening, teaching, reading and playing games with children; ii) physical care, including feeding, bathing, dressing, putting children to bed, iii) accompanying and transporting children, waiting or meeting children, ensuring their safety and handing them over to substitute carers. Physical care and accompanying care must be done regularly and are aggregated in the multivariate analysis as routine care activities.

2) Childcare as a secondary activity. This is time parents record as childcare while doing something else as a primary activity at the same time. Secondary activity is mostly supervising children without active engagement, for example, cooking dinner whilst also watching over children. We use the terms secondary care and supervisory care interchangeably. When childcare is recorded as both a primary and a secondary activity in the same time period, we count it only once.

3) Time spent in children's company (excluding time respondents were sleeping). This captures the total amount of time that parents record that their children were present with them. This time includes the childcare activities specified above, but also encompasses time that parents were participating in nonchildcare activities but were with their children. We also look at two subsets of this time. These are the time parents spend with children in recreation and leisure or social and community interaction i) with children only and ii) with both children and spouse, together as a family. Recreation and leisure includes activities such as sport and outdoor activity, games and hobbies, reading and watching TV, while social and community interaction includes activities such as socializing, attending the cinema, 


\section{Analysis plan}

We conduct bivariate analyses of the time parents spend on childcare activities and in their children's company, showing the average weekly hours spent in each of the dependent variables by year. T-tests are used to identify significant variation across time. We run multivariate regression analyses (OLS) on each of the measures described above. The independent variable of primary interest is survey year $(2006=1)$. We enter education as a binary variable (degree $=1$ ). Employment status is entered as two dummy variables, no paid work $=1$, works part-time $=1$. Full-time work is the omitted category. Age of children is entered as two dummy variables, youngest child is aged 5-9 years $=1$, and youngest child is aged 10-14 years $=1$ (youngest child aged 0-4 years $=0$ ). To see if the effect of education, employment status and age of children has changed over time, we run interactions by year*education, year*employment status and year*age of children. Gender is a key explicator, and we run separate models for mothers and fathers because the control variables do not have the same effect on each gender. Because childcare time is higher the more children in the family (Craig and Bittman 2008), we control for the number of children in the household. We also control for whether formal childcare is used and spouse's employment status, as each of these may impact on the time a parent spends caring for, and in the company of, their children. The reference category is a parent with no college degree, employed full time with one child aged 0-4 years in 1992, who does not use formal care and has a spouse in full-time employment.

\section{Findings}

\section{Descriptive analysis}

The descriptive results suggest that parental childcare time has increased, but that overall time spent in the company of children has not.

Between 1992 and 2006, the time both mothers and fathers spent on primary childcare increased by about 2 hours per week. Disaggregating this, we see that time spent on interactive talk-based care was lower for mothers, but higher for fathers. Physical and accompanying care (routine activities) went up for both genders. Time spent on secondary care was higher, but only significantly so for fathers. It is possible that this reflects a heightened awareness by fathers in 2006 that supervision without active engagement constitutes care. In any event, fathers' time was significantly higher across every category of childcare. For mothers, there appears to have been a trade-off between routine and non-routine care activities, with time spent on interactive talk-based care significantly lower, while time spent in physical and accompanying care was significantly higher.

The lower half of Table II shows the difference in overall time spent with children between 1992 and 2006. (Recall that this is a more encompassing measure than is captured in specific childcare activities.) It reveals that mothers and fathers averaged approximately 2 hours per week less with their children in 2006 than 1992 . The difference is not significant, likely reflecting wide variation between parents, but indicates that overall parentchild time has not gone up. Along with the increase in parents' primary childcare, this suggests that more of the time parents are together with children is spent doing specific childcare activities than it used to be.

Table II: Time spent on childcare activities and with children (mean weekly hours)

\begin{tabular}{|c|c|c|c|c|c|c|}
\hline \multirow[t]{2}{*}{ Mean weekly hours } & \multicolumn{3}{|c|}{ Mothers' time } & \multicolumn{3}{|c|}{ Fathers' time } \\
\hline & 1992 & 2006 & difference & 1992 & 2006 & difference \\
\hline \multicolumn{7}{|l|}{ Childcare activities } \\
\hline Primary childcare & 22.0 & 24.0 & $1.97 * *$ & 7.4 & 9.6 & $2.22 * * *$ \\
\hline Talk care & 10.5 & 9.6 & $-0.87 *$ & 4.2 & 4.9 & $0.69 * *$ \\
\hline Physical care & 9.6 & 10.8 & $1.15^{*}$ & 2.4 & 3.3 & $0.95 * * *$ \\
\hline Accompanying care & 1.7 & 2.5 & $0.83 * * *$ & 0.7 & 1.0 & $0.27 * * *$ \\
\hline Secondary childcare & 19.8 & 21.3 & 1.52 & 6.8 & 8.4 & $1.64 * *$ \\
\hline \multicolumn{7}{|l|}{ Time spent with children } \\
\hline Total time spent with children & 74.1 & 72.0 & -2.07 & 49.1 & 46.8 & -2.36 \\
\hline $\begin{array}{l}\text { Time in recreation/leisure/social activities } \\
\text { with children }\end{array}$ & 15.6 & 15.5 & -0.09 & 16.7 & 16.3 & -0.34 \\
\hline
\end{tabular}




\begin{tabular}{lllllll}
\hline $\begin{array}{l}\text { Time in recreation/leisure/social activities } \\
\text { with children and spouse }\end{array}$ & 11.0 & 10.7 & -0.23 & 14.3 & 14.1 & -0.21 \\
\hline Note: Weighted data; $* * * \mathrm{p}<0.001, * * \mathrm{p}<0.01,{ }^{*} \mathrm{p}<0.05$ & & & &
\end{tabular}

As might be expected, mothers spent substantially more time in their children's company than did fathers. However, fathers spent slightly more time than mothers in recreation, leisure and social activities with their children. Thus a much greater proportion of fathers' than mothers' time with children was spent in recreation. In addition, a greater proportion of fathers' time in leisure with children was shared with their spouse than was the case for mothers. This implies that for some of the time both parents are together with children, fathers are engaging in recreation and leisure, while mothers are not.

In summary, the descriptive results suggest that it is active childcare that has increased over time, rather than the broader category of all time in the company of children. Since active childcare is a subset of all time with children, this implies that during the time they are together, parents were more actively focused on children in 2006 than in 1992. This lends support to the idea that parenting is now more intensive. Also, the greatest changes occurred amongst fathers. They are doing more across the range of childcare tasks, including hands-on routine care.

\section{Multivariate analysis}

We now turn to multivariate analysis to investigate how the effects of parents' gender, education level, employment status and the age of children have changed over time across our measures of parent-child time described above. Full tables are available on request.

\section{Time spent in childcare activities}

\section{Gender}

Controlling for the effects of education, employment, age of youngest child and number of children, mothers did not spend significantly more time on childcare activities in 2006 than 1992. They did do more routine and supervisory care (not quite statistically significant), but this was offset by less interactive talk-based care. In contrast, net of controls, fathers' time in all childcare activities increased significantly. Fathers spent nearly an hour more a week on talk-based care, nearly two hours a week more on routine care, and three hours more on secondary care in 2006 compared to 1992.

\section{Education}

In 1992, highly educated parents spent more time on childcare activities than less-educated parents. This did not extend to interactive talk-based care as might be expected, but was concentrated in routine (physical and accompanying) care and in secondary activity. However, the interaction between year*education shows that this trend was reversed in 2006, most strongly for mothers. Being educated to degree level had less impact on childcare time in 2006 than it did in 1992. This supports our expectation that the effect of education on parentchild time has diminished.

\section{Employment}

Mothers and fathers not in paid work spent more time on all childcare activities than those who were employed full time. However, it should be noted that effect sizes are small, the difference in routine care for mothers is not significant and in the sample there are very few fathers not in paid work. In 2006, though, non-working mothers engaged in more interactive, talk-based care compared to full-time employed mothers in 1992, which may be evidence of more intensive parenting amongst stay-at-home mothers. This may be linked to changes in selection into stay-at-home motherhood. There were no significant differences between the time parents spent on childcare activities if they worked part-time compared to full time, in either 1992 or 2006. Parents also spent significantly less time on childcare (particularly routine care) if their spouse worked part-time or was not in paid work. 
Parents did less active childcare when their children were older. This was slightly more so in 2006 than in 1992. Specifically, compared to 1992, both mothers and fathers in 2006 spent even less time on routine care for 10-14 year olds and fathers spent even less time on secondary care for 5-9 year olds. This suggests that the increase in parents' childcare time between 1992 and 2006 is concentrated on children aged 0-4 years.

\section{Number of children}

Parents generally spent more time on childcare activities the more children they have, with no significant difference between 1992 and 2006.

\section{Formal childcare}

As might be expected, mothers using formal childcare for their children spent less time on primary childcare, comprised almost entirely of less routine care, however they maintained their talk-based care. Fathers' primary and secondary childcare did not change significantly according to the use of formal care.

\section{Time spent with children}

\section{Gender}

The constant terms in the multivariate analyses confirmed that all else being equal, mothers still spend much more time in the company of their children than do fathers. However, as in the descriptive statistics, mothers' and fathers' amount of time spent with children in recreation and social activities is similar. In fact, fathers' predicted time in recreation and social activities with their children was higher than mothers', indicating that a much higher proportion of fathers' than of mothers' time with children is leisure time. Fathers' shared time (i.e. with spouse present also) in recreation with children was also higher than mothers'. Since we are examining data from matched couples, this implies that fathers were recording recreation time with mothers also present, but that mothers were doing something other than recreation, possibly childcare for example. Between 1992 and 2006 there was a reduction in the total time that parents spent in the company of their children; approximately 4 hours for mothers and 3.3 hours for fathers, although net of controls these were only marginally significant.

\section{Education}

Education had no significant effect on total time with children or on recreation and social time with children, either with children only or with children and spouse together, in either 1992 or 2006.

\section{Employment}

As with childcare activities, parents who did not participate in paid work spent significantly more time with their children than those who worked full time. The only difference between 1992 and 2006 was that, for mothers, not being in paid work no longer translated to an increase in shared recreational time together with both their children and their spouse. This is likely because their spouses were working longer hours in 2006 than in 1992, in accordance with the trends discussed above. Mothers who worked part-time spent significantly more time with their children, but not significantly more in recreational and social activities with their children; while fathers who worked part-time spent significantly more time with their children and also in recreational and social activities with children, both alone and shared. There was no difference in the effect of part-time work in 1992 and 2006.

Spouses' employment status did not have a significant impact on total time with children. However, mothers whose spouse worked part-time spent significantly longer in recreation and leisure with their children; and significantly longer in recreation and leisure with their children and spouse if their spouse worked part-time or was not employed. Fathers' recreational and leisure time with children was unaffected if their spouse worked part-time, but if their spouse was not in paid work at all, it was significantly higher.

\section{Age of children}

Generally, the findings showed that the time parents spent with children decreased as they got older. None the less, parents with 5-9 year old children spent a similar level of recreation and social time with children as did parents with a youngest child aged 0-4 years. Also, in 1992, for mothers with youngest children aged 5-9 years, 
recreational time was more likely to be shared with their spouse and children together than was the case for mothers with youngest children under five years old. This effect was largely reversed in 2006, perhaps as a result of higher workforce participation for mothers and longer average hours for men.

\section{Number of children}

Both parents also spent significantly more total time with children if they had more than one child. Having more children resulted in fathers spending significantly more recreational time with their children, but there was no corresponding effect for mothers.

\section{Formal childcare}

Fathers' time with children was largely unaffected by the use of formal childcare. Mothers, however, did spend significantly less time in total with their children if they used formal care, likely also reflecting higher levels of employment if formal care is used. However, recreation and leisure time with children was unaffected for both mothers and fathers, suggesting that parents protected this time, regardless of whether their children were in formal childcare or not.

\section{Discussion and conclusion}

Over recent decades, expectations of good parenting have come to hold that focused, intensive parental attention is essential to children's development. A pervasive discourse suggests that high levels of parental input are a key determinant of children's social, psychological and educational outcomes, with the early years particularly crucial. These ideas seem reflected in behaviour, with cross-national studies consistently finding that parental childcare time has risen over time, even as dual-earner households are increasing. In this paper, we interrogated this trend in more detail than previous research, using Australian time use data from each end of a fifteen year period from 1992 to 2006 . The aim was to provide a more nuanced understanding of parent-child time by examining a range of activities that are subsumed under the broader term 'time with children', and to look for evidence of a shift towards more child-focused and intensive parenting in both the amount and composition of parent-child time. We also identified ways in which the extent of change across our measures of parent-child time differed for mothers and fathers, by parents' employment and education, and by the age of children.

Our findings indicate a compositional change in parental time allocation, which does suggest that parenting is now more intensive. On the one hand, there was a decline in the average time that parents spent with their children aged 0-14 years between 1992 and 2006. This is likely because by 2006 in Australia a higher proportion of both mothers and fathers were employed full time, more mothers were employed part-time rather than being homemakers, and average paid work hours for full-time employees were higher (Craig and Mullan 2009). On the other hand, the time parents spent on active childcare for children aged 0-14 years did not decrease commensurately. All else equal, mothers' childcare activity time stayed fairly constant over the period, and fathers' childcare activity time went up. This suggests that of the time parents were with their children, a higher proportion was spent in childcare activities in 2006 than in 1992. In other words, more active childcare occurred within less overall time. It is also the case that despite averaging less overall time with their children in 2006 than in 1992, parents' time spent in recreation/leisure and social activities shared with children barely changed. Again, this implies efforts to prioritize children, even as work demands increased. The changes in time use composition, with a higher proportion of overall time spent in active childcare and shared parent-child leisure, suggest that the time parents spent with their children was more intensive and child-centred in 2006 than in 1992.

The increase in fathers' childcare time is particularly interesting. Although it did not bring fathers' childcare anywhere near parity with mothers, there was a clear move in this direction. While a greater proportion of fathers' than mothers' time with children is still spent in 'fun' activities, such as talk-based care and in leisure and recreation activities, this is changing slightly. The increase in fathers' childcare time occurred across the range of care activities, including hands-on routine care. Discourses on the active, engaged father may have been influential in encouraging Australian fathers to perform a wider repertoire of care activities, even though lengthening full-time work hours constrained their overall time with children. More of fathers' time is now spent in active childcare than previously, supporting the notion that fathers are an integral part of the trend towards intensive parenting. It also means that counting both mothers' and fathers' inputs, Australian children now are receiving more active parental care than in the past. The increase in fathers' childcare is mainly the result of more time spent in childcare for 0-4 year olds. This suggests that the intensification of parenting is concentrated 
in the 'early years', which is consistent with the discourse on the 'crucial' first three years of life (Bruer 1999). Alternatively, it may be a cohort effect, and mean that younger fathers are more involved than older fathers, and will remain so as children age. It may also be a feature of the increase in maternal employment necessitating fathers' involvement in childcare to a greater extent than previously.

In this study, fathers' changes in time allocation outstripped those of mothers, which is noteworthy because the literature on the gender division of labour has generally found that the most marked changes have been in mothers', rather than in fathers', behaviour (see England 2010 for a discussion). In this study of childcare and time with children, mothers' time was more constant than fathers. Of course, the major change in mothers' time allocation over recent years has been a result of many more becoming employed (Bianchi et al. 2006; Coltrane and Adams 2008; Sayer et al. 2004a; Ehrenreich and English 2005). This pattern was evident in Australia between 1992 and 2006, although mothers were still more likely to work part-time rather than full time. If mothers are devoting more time to paid work yet not reducing their childcare time, it is likely they are decreasing their personal care or child-free leisure time, which Monna and Gauthier (2008) note is a downside of heightened parental time investment in children. The same could be said of fathers for whom time spent in paid work and time devoted to childcare increased between 1992 and 2006.

While the time that mothers spend with children has remained fairly constant overall, the divergence between mothers has grown. In particular, the time difference in interactive talk-based care between non-working and working mothers was greater in 2006 than in 1992. This may be because the composition of the group has changed. Less than 30 per cent of mothers were non-working in 2006, compared to over 40 per cent in 1992. As noted above, this reflects wider social trends in Australia and other western countries. Our results may reflect stronger selection effects operating in 1992 than in 2006. In 2006, full-time motherhood may be a more conscious choice, since it is no longer normative, and these mothers may be using their time to interact with their children. They may subscribe more fully to the ideals of intensive parenting than mothers who remain in the workforce. It may also be relevant that in 2006 young mothers' stay-home period is likely to be more shortlived than in the past, because they take maternity leave rather than relinquish employment entirely. The patterns we note may mean they are consciously spending as much time as possible with children during a limited period of absence from the workforce. The introduction of a national paid parental scheme in Australia in 2011 may exacerbate this trend in the future.

Interestingly, we found that being highly educated had a greater impact on childcare time in 1992 than in 2006.The widespread cross-national finding that education predicts higher time inputs was found in Australia for 1992 but the effect was diminished in 2006.This may be because the discourse on intensive parenting now extends to all education levels, or because educated mothers are more likely to be employed in 2006 than in 1992. It may be that educated mothers are more likely to work in professional occupations, and with these jobs it is particularly difficult to balance work and family, and to find the extra time for children. Also, opportunities to adopt family-friendly work patterns, such as part-time work may be limited in professional roles. A further interpretation is that the marked growth in tertiary education in Australia means it is no longer the marker of class it once was, and the education gradient is no longer as strongly related to particular attitudes or aspirations for children.

There are caveats that should be noted. The discourse on intensive parenting and father involvement may have raised awareness, and as a result parents in 2006 may have recorded 'childcare' time differently to parents in 1992 (particularly secondary activity). The detailed TUS coding minimizes this likelihood for primary activity, and the 'time with' variables measure parental time according to who parents are with, rather than what they consider to be childcare, but it is possible that some of the increase in fathers' secondary childcare reflects greater consciousness that supervision is a form of care. Also, the particularities of the Australian context should be borne in mind in interpreting the results. Factors including the low use of formal day care, high maternal parttime work and long full-time working hours for fathers may mean there are cross-national differences in effects and trends. It seems likely that some of the patterns we identify might be found in the USA, the UK, Canada and New Zealand, which have similar cultural attitudes to child-raising and broadly comparable welfare regimes, but this would need to be tested in future research.

In summary, this paper investigated the extent to which contemporary discourses around parenting were reflected in behavioural changes between 1992 and 2006. And while ideology and behaviour do not necessarily align, with adaptation often lagging behind new thinking, our findings are consistent with the interpretation that emerging ideas on intensive parenting, greater father involvement and the importance of the early years are engendering behavioural change. In particular, a greater proportion of parents' time with children is spent in 
active childcare and in recreation and leisure activities with children, which suggest a greater child focus. Fathers' parent-child time, particularly in physical care, increased more than mothers' (from a much lower base).We also found changes in the impact of education and employment on parental time patterns. Differences between employed and non-employed mothers widened, and tertiary education no longer predicts significantly higher childcare time. Further research could qualitatively explore why these differences manifest and what the findings mean to parents subjectively. This will be the subject of future study.

\section{Notes}

1. Although a time use survey was conducted in 1997, this is excluded from the analysis presented since our focus is on change over the longest time span available.

2. In a number of households, diaries were completed on only one diary day.

3. Separate analysis of these categories was conducted but was not significant (results not shown). This may be due to the small levels of time involved when the different activities are examined independently. In addition to this, we also compared active versus passive leisure time with children. Again results were not significant and are not presented.

\section{Bibliography}

ABS 2006 Australian Social Trends, Cat No. 4102.0, Canberra: Australian Bureau of Statistics.

ABS 2009 'Work, Life and Family Balance, Cat No. 4102.0', Australian Social Trends, Canberra: Australian Bureau of Statistics.

Apps, P. 2006 'Family Taxation: An Unfair and Inefficient System', Australian Review of Public Affairs 7(1): 77-101.

Aurini, J. and Davies, S. 2005 'Choice without Markets: Home-schooling in the Context of Private Education', British Journal of Sociology of Education 26(4): 461-74.

Baxter, J. 2009 Parental Time with Children: Do Job Characteristics Make a Difference? Barton, ACT: Australian Institute of Family Studies.

Baxter, J. 2010 An Exploration of the Timing and Nature of Parental Time with 4-5 Year Olds Using Australian Children's Time Use Data. Research Paper No 45, Melbourne: Australian Institute of Family Studies.

Baxter, J. and Hayes, A. 2007 'How Four Year-Olds Spend Their Days. Insights into the Caring Contexts of Young Children', Family Matters 76: 34-43.

Berghammer, C. 2012 'Time with Children, Time at Work: Changes in Germany between 1991/92 and 2001/02 and in Austria between 1992 and 2008/09', Population Association of America, San Francisco.

Bianchi, S. M., Robinson, J.P. and Milkie, M. A. 2006 Changing Rhythms of American Family Life, New York, Russell Sage.

Bittman, M., Craig, L. and Folbre, N. 2004 'Packaging Care: What Happens When Parents Utilize Non-Parental Child Care' in N. Folbre, and M. Bittman (eds) Family Time: The Social Organization of Care, London: Routledge.

Bonke, J. and Esping-Andersen, G. 2011 'Family Investments in Children: Productivities, Preferences, and Parental Child Care', European Sociological Review 27(1): 43-55.

Brennan, D. 1998 The Politics of Australian Child Care: Philanthropy to Feminism and Beyond, Cambridge, Cambridge University Press.

Bruer, J. T. 1999 The Myth of the First Three Years:A New Understanding of Early Brain Development and Life-Long Learning, New York, The Free Press.

Cabrera, N., Tamis-Lemonda, C., Bradley, R., Hofferth, S. and Lamb, M. 2000 ‘Fatherhood in the 21st Century’, Child Development 71(1): 127-36.

Coltrane, S. and Adams, M. 2008 Gender and Families, Lanham, MD, Rowman \& Littlefield.

Craig, L. 2006a 'Children and the Revolution: A Time-Diary Analysis of the Impact of Motherhood on Daily Workload', Journal of Sociology 42(2): 125-43.

Craig, L. 2006b 'Does Father Care Mean Fathers Share? A Comparison of How Mothers and Fathers in Intact Families Spend Time with Children', Gender \& Society 20(2): 259-81.

Craig, L. 2006c 'Parental Education, Time in Work and Time with Children: An Australian Time-Diary Analysis', British Journal of Sociology 57(4): 553-75.

Craig, L. 2007a Contemporary Motherhood: The Impact of Children on Adult Time, Aldershot, Ashgate Publishing.

Craig, L. 2007b 'How Employed Mothers in Australia Find Time for Both Market Work and Childcare', Journal of Family and Economic Issue 28(1): 69-87.

Craig, L. 2007c 'Is There Really a "Second Shift", and If So, Who Does It? A Time-Diary Investigation', Feminist Review 86(1): $149-70$.

Craig, L. and Bittman, M. 2008 'The Effect of Children on Adults' Time-Use: An Analysis of the Incremental Time Costs of Children in Australia', Feminist Economic 14(2): 57-85.

Craig, L. and Mullan, K. 2009 'The Policeman and the Part-Time Sales Assistant: Household Labour Supply, Family Time and Subjective Time Pressure in Australia 1997-2006', Journal of Comparative Family Studies 40(4): 545-60.

Craig, L. and Mullan, K. 2011 'How Fathers and Mothers Share Childcare: A Cross-National Time-Diary Comparison', American Sociological Review 76(6): 834-61.

Craig, L. and Mullan, K. 2012 'Shared Parent-Child Leisure Time in Four Countries', Leisure Studies 31(2): 211-29.

Craig, L., Mullan, K. and Blaxland, M. 2010 'Parenthood, Policy and Work-Family Time in Australia 1992-2006', Work, Employment and Society 24(1): 1-19.

Craig, L. and Sawrikar, P. 2009 'Work and Family: How Does the (Gender) Balance Change as Children Grow?', Gender, Work and Organisation 16(6): 684-709. 
Daly, K. J. 2001 'Deconstructing Family Time: From Ideology to Lived Experience', Journal of Marriage and Family 63(2): 28394.

Duncan, S. and Edwards, R. 2003 'State Welfare Regimes, Mothers’ Agencies and Gendered Moralities' in K. Kollind and A. Peterson (eds) Thoughts of Family, Gender, Generation and Class: A Festschrift to Ulla Bjornber, Goteberg: Sociology Institute.

Ehrenreich, B. and English, D. 2005 For Her Own Good: Two Centuries of the Experts' Advice to Women, New York, Anchor Books.

England, P. 2010 'The Gender Revolution: Uneven and Stalled', Gender and Society 24(2): 149-66.

Fisher, K. and Robinson, J. 2010 Daily Routines in 22 Countries: Diary Evidence of Average Daily Time Spent in Thirty Activities, Oxford, UK, Centre for Time Use Research, University of Oxford.

Flouri, E. 2005 Fathering and Child Outcomes, Hoboken, N.J., JohnWiley \& Sons.

Furedi, F. 2001 Paranoid Parenting: Abandon Your Anxieties and Be a Good Parent, London, Allen Lane.

Gauthier, A., Smeeding, T. M. and Fustenberg, F. 2004 'Are Parents Investing Less Time in Children? Trends in Selected Industrialised Countries', Population and Development Review 30(4): 647-71.

Gimenez-Nadal, J. I. and Sevilla-Sanz, A. forthcoming 'Trends in Time Allocation: A Cross-Country Analysis', The European Economic Review.

Gornick, J. and Meyers, M. 2003 Families That Work: Policies for Reconciling Parenthood and Employment, New York, Russell Sage.

Gornick, J. and Meyers, M. 2009 ‘Gender Equality: Transforming Family Divisions of Labor’ in E.O. Wright (ed.) Real Utopias Project, London: Verso.

Hall, S. S. 2005 'Change in Paternal Involvement from 1977 to 1997:A Cohort Analysis', Family and Consumer Sciences Research Journal 34(2): 127-39.

Hays, S. 1996 The Cultural Contradictions of Motherhood, New York, Yale University Press.

Hofferth, S. 2001 'Women's Employment and Care of Children in the United States' in T. Van Der Lippe and L. Van Dijk (eds) Women's Employment in a Comparative Perspective, New York: Aldine de Gruyter.

Hook, J. and Wolfe, C. 2012 'New Fathers? Residential Fathers' Time with Children in Four Countries', Journal of Family Issue 33(4): 415-50.

Lareau, A. 2003 Unequal Childhoods: Class, Race and Family Life, Berkeley,CA, University of California Press.

Mannino, C. A. and Deutsch, F. M. 2007 'Changing the Divisions of Household Labour: A Negotiated Process between Partners', Sex Roles 56(5-6): 309-24.

Milkie, M. A., Mattingly, M. J., Nomaguchi, K. M., Bianchi, S.M. and Robinson, J.P. 2004 'The Time Squeeze: Parental Statuses and Feelings About Time with Children', Journal of Marriage and Family 66(3): 739-61.

Monna, B. and Gauthier, A. 2008 'A Review of the Literature on the Social and Economic Determinants of Parental Time', Journal of Family and Economic Issues 29(4): 634-53.

Nadesan,M.H. 2002 'Engineering the Entrepreneurial Infant: Brain Science, Infant Development Toys, and Governmentality’, Cultural Studies 16(3): 401-32.

Nomaguchi, K. M., Milkie, M. and Bianchi, S. M. 2005 'Time Strains and Psychological Well-Being. Do Dual-Earner Mothers and Fathers Differ?', Journal of Family Issue 26(6): 756-92.

OECD 2006 Society at a Glance: OECD Social Indicators, Paris: Organisation for Economic Cooperation and Development.

OECD 2007 Babies and Bosses - Reconciling Work and Family Life: A Synthesis of Findings for OECD Countries, Paris: Organisation for Economic Cooperation and Development.

Orloff, A. 2009 'Gendering the Comparative Analysis of Welfare States: An Unfinished Agenda', Sociological Theory 27(3): 31743.

Pocock, B. 2005 'Work/Care Regimes: Institutions, Culture and Behaviour and the Australian Case', Gender, Work \& Organization 12(1): 32-49.

Quirke, L. 2006 “"Keeping Young Minds Sharp”: Children's Cognitive Stimulation and the Rise of Parenting Magazines, 19592003', The Canadian Review of Sociology and Anthropology 43(4): 387-406.

Reiger, K., Garvan, J. and Temel, S. 2009 'Rethinking Care: A Critical Analysis of Family Policies, Caring and Women's Negotiation of Dependency', Just Policy 50(1): 16-22.

Sandberg, J. and Hofferth, S. 2001 'Changes in Children's Time with Parents: United States, 1981-1997', Demography 38(3): 423-36.

Sayer, L., Bianchi, S. M. and Robinson, J. 2004a ‘Are Parents Investing Less in Children? Trends in Mothers' and Fathers’ Time with Children', American Journal of Sociology 110(1): 1-43.

Sayer, L., Gauthier, A. and Furstenberg, F. 2004b ‘Educational Differences in Parents’ Time with Children: Cross-National Variations', Journal of Marriage and Family 66(5): 1152-69.

Schaub, M. 2010 'Parenting for Cognitive Development from 1950 to 2000: The Institutionalization of Mass Education and the Social Construction of Parenting in the United States', Sociology of Education 83(1): 46-66.

Shaw, S. 2008 'Family Leisure and Changing Ideologies of Parenthood', Sociology Compass 2(2): 688-703.

Shaw, S. and Dawson, D. 2001 'Purposive Leisure: Examining Parental Discourses on Family Activities', Leisure Sciences 23(4): $217-31$.

Smith, A. 2004 'Who Cares? Fathers and the Time They Spend Looking after Children', Sociology Working Papers, Oxford: University of Oxford.

Stearns, P. N. 2003 Anxious Parents. A History of Modern Childrearing in America, New York, New York University Press.

Sullivan, O. 2006 Changing Gender Relations, Changing Families: Tracing the Pace of Change Over Time, New York, Rowman and Littlefield.

Toohey, M. and Beer, G. 2004 'Financial Incentives to Work for Married Mothers under a New Tax System', Australian Journal of Labour Economics 7(1): 53-69.

Vincent, C. and Ball, S. J. 2007 “"Making up” the Middle-Class Child: Families, Activities and Class Dispositions', Sociology 41(6): 1061-77.

Wall, G. 2004 ‘Is Your Child's Brain Potential Maximized?: Mothering in an Age of New Brain Research’, Atlantis 28(2): 41-50. 
Original article available at: https://doi.org/10.1111/1468-4446.12035

Wall, G. 2010 'Mothers' Experiences with Intensive Parenting and Brain Development Discourse', Women's Studies International Forum 33(3): 253-63

Wall, G. and Arnold, S. 2007 'How Involved in Involved Fathering? An Exploration of the Contemporary Culture of Fatherhood', Gender and Society 21(4): 508-27.

Whitehouse,G., Baird, M., Diamond, C. and Soloff, C. 2007 'Parental Leave in Australia Beyond the Statistical Gap', Journal of Industrial Relations 49(1): 103-12.

Wrigley, J. 1989 'Do Young Children Need Intellectual Stimulation? Experts' Advice to Parents, 1900-1985', History of Education Quarterly 29(1): 41-75.

Yeung, W. J., Duncan, G. J. and Hill, M. S. 2000 'Putting Fathers Back into the Picture: Parental Activities and Children's Adult Outcomes', Marriage \& Family Review 29(2-3): 97-113. 